\title{
Mediações contemporâneas: tradução cultural e literatura comparada
}

Sandra Regina Goulart Almeida Recebido em 01/06/2011 - Aprovado em 27/08/2011

\section{Resumo}

O trabalho aborda o conceito de tradução cultural na contemporaneidade e, em especial, as propostas da teórica Gayatri Chakravorty Spivak, refletindo principalmente sobre a relação entre tradução e subalternidade, solidariedade e literatura comparada.

Palavras-chave: tradução cultural; subalternidade; solidariedade; literatura comparada. 
Como uma tradutora, então, enceno a contradição, a contra-resistência, que está no âmago do amor (Spivak, 2000, p. 24). ${ }^{1}$

\section{Exórdio: as teias da tradução}

A tradução tem ocupado um lugar de destaque nos estudos literários e culturais como mecanismo proeminente de engajamento teórico-crítico tanto com os instrumentos de produção acadêmica quanto com os repertórios culturais da contemporaneidade. Sua relevância é atestada em inúmeros trabalhos, produzidos tanto no Brasil quanto no exterior, em especial na década de 70/80 e no início da década de 90, período considerado por muitos críticos com sendo o momento pós-moderno da tradução. ${ }^{2}$ Longe de terem esmaecido no século 21 , os estudos críticos da tradução, principalmente com a chamada virada cultural iniciada no século anterior, tornaram-se objeto de reflexão contínua, nesse outro momento histórico marcado em especial pelos movimentos globais, translocais, transnacionais e transculturais. É, em primeiro lugar, a longa trajetória teórica da crítica indiana, radicada nos Estados Unidos, Gayatri Chakravorty Spivak pelos meandros da tradução como crítica pós-colonial e cultural que me proponho a mapear e problematizar neste trabalho. Porém, antes de abordar sua pertinente e exemplar reflexão sobre a temática, inicio este exórdio com três cenas que dramatizam a tradução como uma prática crítica de ressignificação cultural que, de certa forma, segue a esteira teórica proposta por esta reflexão.

Cena 1 - (In) Traduzibilidades: "Ela sonhou que chovia e assim não podia sair para se encontrar com ele como planejado. Não podia andar através das águas hostis, arriscar-se a borrar a tinta das páginas que ele havia pedido a ela que traduzisse (...) Ela tinha medo da chuva, tinha medo da neblina e da neve que chegavam a este país, tinha medo até mesmo do vento. (...) No ano passado quando a cidade ficou escura com tanta neblina, ela se escondeu dentro de casa por quatro dias" (ABOULELA, 1999, p. 3). Com essas palavras a narradora do romance $A$ tradutora [The Translator], da escritora sudanesa Leila Aboulela, inicia a narrativa de Sammar, relatando seu pavor, seu desespero e sua dor ao ser confrontada com a incomensurável experiência da tradução cultural. Como uma personagem do trânsito, nascida na Escócia de pais sudaneses, tendo crescido no Sudão e agora de volta à

1 A menos que esteja indicando nas referências bibliográficas, todas as traduções são de minha própria autoria.

2 Ver, por exemplo, o trabalho de Else Vieira, Por uma teoria pós-moderna da tradução (1992). Escócia, Sammar - ela própria sujeito da tradução e seu objeto - tipifica a experiência da contemporaneidade como um ato tradutório e também como uma experiência ambivalente por definição. Sammar personifica tanto a informante nativa, nos termos definidos por Spivak (1999), quanto a imigrante que atua como agente das trocas culturais, uma vez que, ao assumir o papel de tradutora oficial na Universidade de Aberdeen, ela traduz ao 
mesmo tempo em que vai aos poucos sendo também traduzida. O sentimento de dificuldade e mesmo de impossibilidade de "entregar" a tradução do árabe para o inglês do manifesto político do grupo islâmico Al-Nidaa, da qual havia sido incumbida de realizar a pedido de um professor, especialista em estudos do oriente médio, se mescla ao constante temor diante daquilo que lhe é diferente - metaforizado pela chuva, pela neblina e pela neve - que costumeiramente envolve a cidade nórdica na qual é estranha e estrangeira. Aqui é a recorrente metáfora da neblina, assim como ocorre em Coração das trevas, de Conrad, conforme relata Homi Bhabha (1994), que torna significativa a atividade tradutória transcultural- como algo que encobre e oculta, que impede a clareza, o discernimento e o entendimento - mais do que a costumeira evocação da ponte como ligação e elo do ato tradutório, sobre a qual no fala Sherry Simon (1996). O sonho (ou pesadelo) de Sammar, elemento central para a religião islâmica, revela o ardil da experiência tradutória na contemporaneidade: a impossibilidade material da tradução que se esfacela frente ao tenebroso terreno da incerteza tradutória e do risco iminente aqui simbolicamente evocado pelas imagens da neblina e das águas hostis. É ainda a tarefa e a responsabilidade de ter que traduzir um texto de um grupo revolucionário e marginalizado, sem voz ou poder, escrito em uma linguagem própria desses grupos - "um manuscrito, pessimamente fotocopiado e cheio de erros de ortografia" (ABOULELA, 1999, p. 23) -, para uma língua hegemônica (o inglês) que a coloca nesse estado de incerteza e indeterminação, sendo essa a fonte do pesadelo revelador. No entanto, a tradução jaz realizada pela própria necessidade de inserção do sujeito como tradutor no espaço habitado por Sammar - espaço esse indelevelmente marcado pela inexorabilidade do ato tradutório. Temos, então, por um lado a inerente impossibilidade de concretude e o limite da tradução; por outro, a inevitabilidade de sua condição.

Cena 2 - Violações: Harold Cardinal, indígena da etnia cree do Canadá, diante do impasse político criado pela desarticulação entre o governo e os indígenas sobre o conceito de identidade e cidadania canadenses, afirma: "Acredito que parte de nosso problema comunal se deva ao fato de nunca ter havido nenhuma tradução precisa entre as línguas dos indígenas e dos brancos" (1992, p. 191). Cardinal se refere especificamente à falta de compreensão do governo e dos "brancos", que não conseguem "decifrar" o profundo significado que os indígenas cree atribuem ao termo Ka-kanata-Aski, que quer dizer "a terra que é limpa", nem a "sou um Nee-you", uma palavra descritiva e complexa que implica um intrínseco vínculo com o povo e a terra através da qual os cree se sentem unidos. É o termo usado no lugar de "sou um cree", que descreve um grupo de indígenas, mas não como eles se nomeiam. Acrescenta Cardinal, "é difícil para um 
homem branco, sem entender a cultura indígena, saber o que alguém quer dizer quando diz, 'sou um membro de um povo que é parte da Mãe Terra' (...). É uma definição religioso-cultural de ser um canadense" (1992, p. 190). Para Cardinal, essa diferença na definição dos termos e no processo de nomear, bem como o abismo criado pela falta de compreensão entre as partes, levou o governo a adotar como prática política para a definição de cidadania conceitos que não teriam "equivalência" linguística para os crees - como os de assimilação e de integração -, demonstrando um profundo desconhecimento linguístico e cultural e um violento desrespeito à diferença e às crenças indígenas. Cardinal clama, assim, para o seu povo "o direito de significar como um ato de tradução cultural" (BHABHA,1994, p. 132).

Cena 3 - Silenciamentos: A terceira cena remete a uma história conhecida entre nós. Audálio Dantas, jornalista que "descobre" a escritora brasileira, afro-descendente e moradora de favela Carolina Maria de Jesus e serve de "mediador" ao publicar seu livro Quarto de despejo, em 1960, afirma:

A repetição da rotina favelada, por mais fiel que fosse, seria exaustiva. Por isso foram feitos cortes, selecionados os trechos mais significativos. (...) Carolina viu a cor da fome - a Amarela. No tratamento que dei ao original, muitas vezes, por excessiva presença, a Amarela saiu de cena, mas não de modo a diminuir a sua importância na tragédia favelada. (2001, p. 3).

Não obstante o relevante papel de Dantas na acolhida que dá ao diário de Carolina, esse surge, ainda hoje, filtrado pela perspectiva desse editor, que "traduz" o pensamento da escritora e sua própria noção de representação. No papel de mediador e tradutor, Dantas elimina do livro o que lhe incomoda e modifica as ideias e as imagens nele contidas com o objetivo de traduzir a experiência de uma mulher marginalizada; porém, silenciando e congelando o sujeito subalterno em um espaço exótico e de suposta autenticidade fetichizada.

Essas três cenas ensejam leituras complementares do ato tradutório, principalmente no contexto das traduções culturais na contemporaneidade. Evocam, em especial, uma teorização que me interessa em particular e que pode ser vislumbrada em várias reflexões de Spivak sobre uma teoria da tradução embasada em especulações sobre a subalternidade, a alteridade, a pós-colonialidade e a literatura comparada. Proponho, portanto, trilhar o itinerário da tradução pós-colonial e cultural principalmente aquela elaborada por Spivak, mas também indo além de seu percurso, enfocando os momentos centrais de sua teorização: os prefácios como textos teóricos, o conceito de intimidade da tradução, a tradução cultural e a subalternidade e a literatura comparada como tradução. 
O posicionamento de Spivak ressoa o de Lefevere segundo o qual "o estudo da tradução pode nos ensinar algumas coisas não apenas sobre o mundo da literatura, mas também sobre o mundo em que vivemos" (apud Lages, 2002, p. 76). Como discutirei a seguir, a prática tradutória sobre a qual discorre Spivak se move além de um exercício apenas teórico ou confinado ao âmbito dos estudos literários para falar também da tradução cultural como prática de atuação política.

4 Insisto aqui e em várias passagens deste artigo na marcação de gênero feminino para ser fiel à inúmeras teorizações da autora sobre a invisibilidade do feminino, especialmente com relação à tradução. Ver, por exemplo, sua pertinente discussão, em Pode o subalterno falar (2011), sobre a violência epistêmica causada pela tradução equivocada de sati (que significa apenas "boa esposa") e que se transforma no termo que designa o ritual de imolação das viúvas.

5 Spivak desenvolve sua teoria da tradução em vários textos que serão aqui discutidos, entre eles "Translator's Preface" - Of Grammatology (1976), "The Politics of Translation" (1993), "Translator's Preface" Imaginary Maps (1995), "Translation as Culture" (2000), "Questioned on Translation: Adrift" (2001), "Translation into English" (2005), "More thoughts on Cultural translation" (2008), "Rethinking Comparativism" (2009), "Nationalism and the Imagination" (2010).

6 O pensamento pós-moderno sobre a tradução tende a concebê-la como um caso específico de leitura e o tradutor como produtor de significados próprios independentes das pressuposições do original (cf. Rodrigues, 2000, p. 221). Haroldo de Campos vê a tradução como "uma operação de leitura radical"' (1981, p. 175). Ver também a teoria da leitura em Benjamin (Lages, 2007 , p. 216), bem como em Santiago $(1971,2000)$.

\section{Para além dos prefácios}

O conceito de tradução não apenas perpassa toda a obra de Spivak, mas também se insere persistentemente em sua prática acadêmica e em seu projeto pedagógico, que se instaura a partir das relações entre produção cultural e contexto sóciohistórico. A atividade de tradução surge de forma recorrente em seu trabalho teórico ao longo de mais de três décadas (de 1976 até 2010) como uma dimensão reflexiva que subjaz sua crítica da linguagem, da cultura, da pós-colonialidade, da literatura comparada e, principalmente, do trabalho intelectual contemporâneo. Como nos lembra Augusto de Campos, "tradução é crítica (...) uma das melhores formas de crítica" (1978, p. 7). Como se estivesse fazendo coro a essas palavras, Spivak traz no bojo de seu trabalho teórico uma reflexão sobre a tradução como ato simbólico e crítico. ${ }^{3}$

Renomada tradutora da Gramatologia [Of Grammatology] (1976), de Jacques Derrida, para o inglês, trabalho que a lança como uma das mais importantes críticas da atualidade, Spivak dedica nada menos do que 78 páginas ao que ela denominou de "prefácio da tradutora" ${ }^{4}$, no qual teoriza o papel da tradução por meio de uma elaborada e intricada argumentação desconstrutivista. Spivak é ainda a tradutora de Mapas imaginários [Imaginary Maps] (1995), coletânea de contos de Mahasweta Devi, escritora indiana, que escreve em bengali (uma das línguas oficiais da Índia). Verteu ainda várias outras obras de Devi para o inglês, além de Song for Kali: A Cycle de Ramproshad Sem (2000). O trabalho da prática tradutória é para Spivak uma tentativa de unir sua crítica desconstrutivista e o legado da crítica pós-colonial, assim como de ancorar sua crítica linguística e pós-estruturalista (marcadamente de vertente francesa) a sua filiação histórica e ideológica ao pós-colonialismo e ao feminismo, através da prática tradutória. Nessas vertentes críticas, aparentemente de difícil conciliação, a política e a poética da tradução que Spivak vai, aos poucos elaborando, ganha corpo e densidade teórica em vários de seus artigos, bem como em seus renomados "prefácios da tradutora". ${ }^{5}$

No prefácio de Gramatologia, Spivak apresenta as primeiras reflexões e as bases de uma teoria da tradução entendida como um processo de leitura múltiplo, informado por uma rede intertextual de significados e aberto a uma infinidade de traduções possíveis, construídas com base na diferença. ${ }^{6}$ Remete, assim, ao pensamento pós-moderno sobre a tradução que tende a concebêla como um caso específico de leitura e o tradutor como produtor de significados próprios independentes das pressuposições do original, como atestam vários críticos, em especial Else Vieira (1992). Evocando Derrida em Torre de Babel, que por sua vez se reporta ao influente texto de Walter Benjamin, "A tarefa do 
Ver a teorização de Derrida acerca da tradução em Positions (1982), bem como seu "Des tours de Babel" (1985). Ver também o livro organizado por Joseph Graham (1985) que teoriza a "diferença na tradução" a partir dos postulados de Derrida. Assim como a noção de tradução como transformação de Haroldo de Campos (1981, p. 191).

8 Ver o comentário de Stephen Morton sobre a observação de Denis Donoghue de que a tradução de Spivak do texto de Derrida é "deliberadamente literal em sua tentativa de transmitir as nuances filosóficas do pensamento de Derrida" (Morton, 2007, p. 44). Em outro momento, indagada se acredita na fidelidade ao original, Spivak afirma que" sim, não porque é uma tarefa possível, mas porque é preciso tentar" (2001, p. 14). No entanto, o conceito de fidelidade para Spivak, como veremos, pressupõe a responsabilidade ética do tradutor para com o texto a ser traduzido.

9 O termo double bind, adotado por Derrida em sua crítica desconstrutivista, se refere a uma situação (impasse ou dilema) no qual é preciso escolher entre duas alternativas não satisfatórias quando demandas contraditórias são efetuadas.

${ }^{10} \mathrm{O}$ argumento de Lages se refere à uma suposta resposta a ser dada pelo questionamento da dimensão da perda na tradução. À pergunta: o que se perde no caso da tradução, obteríamos uma resposta que se traduz nessa negatividade que é também uma afirmação: "o inefável, o intangível, a imediaticidade" (Lages, 2007, p. 237).

11 Ver as possíveis traduções do prefixo mis do inglês para o português: mal-,des-, dis-, in-. Indica também "má" ou "erro" (Webster's Dicionário Inglês-Português). tradutor," a autora afirma que se "a tradução é necessária, mas impossível", ela é também "não apenas necessária, mas inevitável" (2000, p. 13-22).7 Para Spivak, a tradução é definida por "sua diferença do original, esforçando-se em direção a uma identidade" (2001, p. 21). Assim, seguindo a teorização de Derrida que admite ao mesmo tempo em que nega a tradução (isto é, chama a atenção para a simultânea necessidade e impossibilidade da tradução), pois questiona o privilégio do suposto "original", Spivak argumenta que, ao desejar ao mesmo tempo conservar o "original" (em uma tradução considerada "deliberadamente literal" $)^{8}$ e seduzida pela inexistência de uma autoridade do texto, a tradução se torna uma impossibilidade, revelando ao mesmo tempo a autoridade e fragilidade desse suposto "original". Em outros textos, a teórica afirma que a tradução é "não somente necessária, mas inevitável"; porém, "na medida em que o texto guarda seus segredos, ela se torna impossível" (2005a, p. 58). Não se trata aqui da histórica crença no "preconceito da inferioridade ou da impossibilidade da tradução", conforme discute apropriadamente Rosemary Arrojo (1986, p. 25). A noção de impossibilidade de tradução evocada por Spivak, via Derrida, parte de outro sentido que se baseia no "caráter paradoxal do próprio gesto tradutório" (LAGES, 2007, p. 30).

A tradução encontra-se, assim, em um dilema ou impasse, em um double bind, ou seja, denota também um suposto "duplo vínculo" que, pela própria definição, remete algo contraditório e pardoxal (SPIVAK, 1976, p. 1xxxvi). ${ }^{9}$ Ao traduzir pressupomos uma transferência de conteúdo sabendo que tal transferência não pode ser efetuada a contento e é a esse dilema que a tradução escrupulosa deve aludir. Para Spivak, "a impossibilidade da tradução é o que coloca sua necessidade em um double bind. É um local ativo de conflito, e não uma garantia irredutível" (2005b, p. 105). A tradução se efetua, então, no espaço conflituoso, mas também produtivo, entre o traduzível e o intraduzível. Como o pharmakon de Derrida - um remédio e ao mesmo tempo um veneno - toda tradução seria uma inevitável "tradução incorreta" (nas palavras de Derrida: mistranslation). Note-se também a negatividade evocada pelo termo que aponta para "um movimento que só se constitui como duplo (ao negar algo, esse algo é afirmado)" (LAGES, 2007, p. 237). ${ }^{10}$ Assim, o termo mistranslation ou tradução incorreta ao mesmo tempo em que evoca o conceito de uma tradução errônea traz em seu bojo sua própria afirmação e também sua negação, pois, afinal, se refere a uma "má tradução" ou mesmo uma in (evocado pelo prefixo inglês mis ${ }^{11}$ ) tradução nos termos evocados por Augusto de Campos, que alude ao termo se referindo à confluência entre introdução e tradução, mas também a sua simultânea negação e inserção (evocado pelo prefixo in-), pois o termo "nega-conserva a própria ideia de tradução" e "se propõe conduzir, texto adentro, a um fim por 
definição inalcançável", buscando assim sua própria identidade na diferença (ASCHER, 1989, p. 150). ${ }^{12}$ Nesse sentido, cada "leitura" produz um simulacro de um suposto original perfazendo uma pluralidade e uma multiplicidade textuais. Toda leitura é uma tradução e, assim, "o erro ou a errância é parte do jogo da leitura" (2001, p. 14). Spivak conclui então que "a tradução é uma versão da intertextualidade que atua também dentro da mesma linguagem" (1976, p. lxxxvii). Ao se referir à tradução como intertextualidade, Spivak se reporta indiretamente ao conceito de dialogismo de Bakhtin, via o conceito de intertextualidade teorizada por Kristeva (1974), ${ }^{13}$ que tem uma relevância especial na reflexão da autora sobre a tradução e a subalternidade, como discutirei a seguir.

Ao concluir outro "Prefácio da tradutora" (1995), em Mapas imaginários de Devi, Spivak evoca uma imagem significativa que ressurge mais adiante em outros textos: a da tradução como um ato infindável de tecer, um ato invisível de urdir, reparar, consertar, cortar e colar com paciência e respeito - como o trabalho de citação, recorte e colagem a que alude Compagnon (1996) - que é cuidadosamente orquestrado por um/a tradutor/a (como leitor/a) em um incessante processo de vaivém na tentativa de ler as narrativas que compõem a substância de uma cultura. Assim, nesse trabalho cuidadoso e meticuloso de tessitura, mais do que uma "metáfora" que descreve a experiência ambígua daqueles que vivem entre culturas (SIMON, 1996, p. 134), a tradução seria uma "catacrese" - algo já absorvido, corrente e inerente ao processo tradutório. Nesse caminho teórico, Spivak segue a trilha da psicanalista Melanie Klein, segundo a qual o trabalho de tradução é "um movimento de vaivém, um translado incessante" que dá origem a um sujeito responsável e ético, ou seja "a constituição do sujeito na responsabilidade é um certo tipo de tradução" (2005a p. 43). Assim, a tradução perde seu sentido literal, assu-

12 O conceito de "intradução" elaborado brevemente por Augusto de Campos e resgatado por Archer e nesta minha reflexão difere do conceito adotado por Pascale Casanova, segundo o qual a "intradução", em oposição à "extradução", seria "uma maneira de agrupar recursos literários, de importar de certa forma grandes textos universais para uma língua dominada (portanto para uma literatura desprovida), de desviar um legado literário" (2002, p. 170)

13 Ver também a relação intertextual da tradução sobre a qual Haroldo de Campos se refere (1992). mindo outros significados em substituição àqueles já existentes, que se movem além da origem da palavra. A tradução se torna então algo mais do que, como a etimologia indicaria, o simples ato de "conduzir através de" (tra+dução), de "transferir" significados. A partir de Klein, Spivak desenvolve um de seus mais contundentes ao afirmar que "tornar-se humano é um economia incessante de tradução" (2001, p. 14), assim como "ser humano é estar comprometido com o outro" (1999b, p. 44). No sentido geral, a tradução instaura algo mais do que ato de "conduzir através de", de "transferir" significados, pois estaria no cerne da constituição do sujeito (2005a, p. 44). Já no sentido estrito, o do/a tradutor/a que traduz a partir de uma língua e narrativas constituídas, a tradução é um também um ato de reparação, de obrigação, de dívida e de responsabilidade. Essa articulação, a partir de Klein (a fantasia como um tecido que se vai tecendo, a consideração/culpa pelo outro, os lugares cambiantes do sujeito), 
tem um impacto marcante em sua concepção de tradução cultural (assim como as teorizações de Bakhtin, Benjamin e Derrida).

\section{Pela intimidade da tradução}

Em seu mais reconhecido texto teórico sobre o assunto, "A política da tradução", de 1992, Spivak inicia seu argumento seguindo ainda a lógica derridiana para então se aprofundar em outros aspectos que redirecionam seu trabalho teórico sobre a tradução para um enfoque mais persistente na critica pós-colonial e cultural. Partindo da consideração de que a linguagem é um processo de construção de significado, um meio através do qual fazemos sentido das coisas e de nós mesmos e, assim, produzimos nossas identidades, Spivak ressalta que a tradução nos permite esse contato com uma linguagem que pertence a vários "outros". $\quad$ Na base de seu argumento está a noção de sedução do texto (e não do/a tradutor/a, numa inversão do sentido etimológico negativo de "engano e negação", aludindo ao sentido de "levar para o lado, desviar do caminho") e a concepção da tradução como o mais íntimo ato de leitura que faz com que o/a tradutor/a seduzido pelo texto a ser traduzido (desviado de seu caminho inicial) a ele se entregue e se renda. Assim, o/a tradutor/a deve tentar "compreender as pressuposições do escritor", isto é, "entrar nos protocolos do texto" (Derrida), não nas leis gerais da linguagem, mas nas leis específicas desse texto (que tem uma história e uma geografia próprias) e isso requer um contato próximo com esse texto através de uma leitura aprofundada, crítica e, principalmente, íntima (2005b, p. 93-94). Percebo na teorização de Spivak certa inspiração na proposta benjaminiana de que "a tradução tende a expressar o mais intimo relacionamento das línguas entre si" (2001, p.191, minha ênfase). Benjamin acrescenta ainda que "a tradução deve, ao invés de procurar assemelhar-se ao sentido do original, ir configurando, em sua própria língua, amorosamente, chegando até aos mínimos detalhes, o modo de designar do original" (2001, p. 201, minha ênfase). A tradução é, assim, como coloca Spivak, um ato de amor, de entrega, de solidariedade, uma relação próxima e de afeto para com o outro e que aproxima o eu do outro, como aponta a epígrafe que abre este.

Alguns críticos viram nessa argumentação uma proposta do "erótico na tradução" (Sherry, 1996, p. 143-149), de um erotismo da submissão ou de uma poética da sedução da tradução (Papastergiadis, 2000, p. 141). Prefiro pensar nessa "intimidade da tradução" (2000b, p. 21) em termos de uma poética e política da "hospitalidade" na tradução - hospitalidade essa teorizada tanto por Lévinas quanto por Derrida - que aparece implicitamente na proposta de uma política da tradução para Spivak, principalmente se pensarmos na "sedução" como um "desvio" 
de um caminho previamente estabelecido. A hospitalidade aqui implica o ato de estar com o outro, de assumir a responsabilidade pelo outro (no sentido tanto de Klein quanto de Bakhtin), uma possibilidade, por vezes negada e por isso mesmo questionada, de uma acolhida incondicional do outro enquanto outro, resguardando o respeito pelo outro e a aceitação de sua diferença por meio de um aprendizado ético, de uma "ética da hospitalidade ${ }^{114}$ Como a ambivalência inerente à impossibilidade e à necessidade da tradução, a hospitalidade aparece também como um conceito paradoxal (já presente na etimologia dos termos hospitalidade e hostilidade - hostis), que deriva da dificuldade e mesmo impossibilidade de aceitação incondicional do outro. A questão da língua está também atrelada à experiência da hospitalidade, pois o "convite, a acolhida, o asilo, o albergamento passam pela língua ou pelo endereçamento ao outro", pois como lembra Derrida, “a língua é hospitalidade" (2003, p. 117). É nesse sentido que a tradução ensejaria, a meu ver, um ato de hospitalidade para com o outro que está no cerne da responsabilidade ética para com esse outro, uma responsabilidade da ordem do direito mais do que do dever.

Spivak destaca, assim, dois aspectos a serem considerados em sua teoria sobre a tradução: a) a tarefa do/a tradutor/a; b) a prática do trabalho de tradução, pressupondo, através dessa reflexão, um aspecto político e outro estético que estão fortemente imbricados entre si. No primeiro caso, é importante pensar no papel desse/a tradutor/a cultural (de uma língua do terceiro mundo), que deve estar atento a aspectos ideológicos quando traduz para o inglês - uma língua que tem uma função política específica e complexa no contexto global atual. No segundo caso, destaca-se o que Spivak denomina de "retoricidade" (em alguns textos a autora fala de idiomaticidade) linguística do texto "original" - ou seja, a natureza retórica da linguagem em oposição ao que Simon denomina de "sua sistematização lógica" (1996, p. 142) ou sua diferença com relação a uma lógica transparente ao se acessar o original. Dessa forma, Spivak propõe uma poética da tradução que, ao ser solidária e hospitaleira com o texto original,

${ }^{14} \mathrm{O}$ argumento de Spivak parece retomar a teorização de Antoine Berman em L'épreuve de l'etranger (1984) que defende a necessidade de uma ética da tradução que permeie um novo conceito de crítica da tradução. Ver também Simon (1996). Ainda segundo Derrida, a ética, ou a responsabilidade do eu para com o outro, não pode existir sem a violência da escrita $(O f$ Gramatology, p. 61) esteja também ciente da possibilidade de violência epistêmica, rendendo-se ao texto, sendo "literal" através de um aproximação intensa com o texto e sua língua. Aqui Spivak critica o ato de tornar um texto mais acessível, pois ao tentar simplesmente transferir conteúdo de uma língua aprendida rapidamente, o/a tradutor/a estaria "traindo o texto" ao mesmo tempo em que estaria demonstrando seu dúbio senso político. Ao ser solidário/a e hospitaleiro/a para com o texto "original", o/a tradutor/a deve render-se a ele pela aproximação intensa com o texto e sua linguagem e deve também estar ciente do risco imanente da violação e da violência epistêmica. Assim, ao falar em intimidade, solidariedade e, mesmo, hospitalidade, segundo minha leitura, 
como uma posição teórica, Spivak declara que a primeira obrigação do/a tradutor/a cultural é "aprender" profundamente (no sentido ético) a língua materna do texto a ser traduzido: "esta é a preparação para a intimidade da tradução cultural", esta é a "tarefa", a obrigação, o dever do/a tradutor/a. Nesse sentido, como não se pode "apenas ler livros que, supostamente, traduzem 'outras culturas'" e nem "aprender todas as línguas do mundo", a tradução se faz imprescindível como um fenômeno complexo de responsabilidade ética singular (2005a, p. 51).

\section{Tradução cultural e subalternidade}

Encontra-se na teorização de Spivak sobre a tradução alguns dos pressupostos centrais apresentados em seu renomado texto de 1988, "Pode o subalterno falar?" Há uma intrínseca relação, que tem escapado a muitos críticos, entre a teoria, a política e a poética da tradução para Spivak e seu persistente argumento de que o subalterno não pode falar. ${ }^{15}$ Como o processo de fala se caracteriza por uma posição discursiva, uma transação entre falante e ouvinte e, nesse sentido, esse espaço dialógico de interação (na acepção de Bakhtin) não se concretiza para o sujeito subalterno que, desinvestido de qualquer forma de agenciamento, é silenciado, pois nenhuma fala é fala se não é ouvida. Sendo assim, devem-se criar espaços por meio dos quais o sujeito subalterno possa falar, trabalhando contra a subalternidade - essa é a questão dialógica propositiva para a autora. Essa é também a responsabilidade e a obrigação como reparação que Spivak reserva tanto ao/a intelectual contemporâneo/a quanto ao/a tradutor/a transcultural - a responsabilidade de abrir espaço discursivo para que o outro fale como um direito através do aprendizado da escuta qualificada, e de estar atento/a para reconhecer a sua inerente cumplicidade e sua suposta benevolência. Esse ato requer, então, um trabalho contínuo de questionamento e intervenção discursiva teórica e prática que passa necessariamente pelo papel relevante do/a tradutor/a cultural.

É nesse contexto que Spivak reitera insistentemente que o/a tradutor /a deve em primeira instância "aprender" a língua materna do texto a ser traduzido, não apenas no sentido lin-

${ }^{15} \mathrm{O}$ termo subalterno, Spivak argumenta, descreve, portanto, "as camadas mais baixas da sociedade constituídas pelos modos específicos de exclusão dos mercados, da representação política e legal, e da possibilidade de se tornarem membros plenos no estrato social dominante" (Spivak, 2000a, p. xx), "aqueles excluídos da mobilidade cultural" (2005a, p. 52). guístico, mas principalmente no sentido de aprender a aprender com o outro, de estar aberto/a ao outro, de fazer da escuta da fala do outro seu objeto de tradução, desfazendo-se, assim, de seus próprios privilégios de fala e de intervenção (um conceito construído a partir de sua noção de "fidelidade", conforme discutida acima). Essa prática endossaria uma tradução que se efetua por meio de uma responsabilidade ética, de um trabalho de um/a leitor/a-como-tradutor/a que se afasta de si mesmo - um movimento de "perda" similar àquele evocado por Benjamin - e faz um movimento através da linguagem em direção ao outro 
- um outro que na prática tradutória de Spivak é identificado com o subalterno. Essa perda, no entanto, ao invés de remeter à condição inerente do trabalho tradutório - que é uma perda irrecuperável, mas necessária, segundo Benjamin - se concretiza para Spivak através da ética do/a tradutor/a, da perda como solidariedade, hospitalidade, respeito e escuta e, principalmente, da perda daqueles privilégios que detêm com relação ao subalterno.

É nesse sentido que o paradoxo da tradução requer que o/a tradutor/a enfrente "a responsabilidade ao traço do outro". Spivak afirma: "devo sugerir que se pense no traço ao invés de se pensar na tradução levada a cabo, concluída: o traço do outro, o traço da história, e mesmo os traços culturais" (2005b, p. 105). A responsabilidade a esse "traço"16 do outro, isto é, à marca, aos vestígios, resíduos e rastros desse outro no contexto social, cultural e histórico (àquilo que ele traz consigo sem às vezes perceber) aqui se refere à singularidade ética, ao acolhimento,

16 O termo "traço" utilizado recorrentemente por Spivak (que também tem o sentido de rastro, pista, trilha, resíduo, vestígio, marca) provém da teorização de Derrida (la trace) que segue o lastro das teorias linguísticas e psicanalíticas. Spivak opta por manter o termo traço, mas evocando também o sentido de rastro e trilha. O traço é aquilo que "sobra ou fica fora e deixa uma marca" que "desenha trilhamentos" (Rego, 2006, p. 15), enquanto que para Derrida, o traço "é a diferença impalpável e invisível entre os trilhamentos" (1976, p. 180). Em português, os tradutores de Gramatologia observam que o termo francês, la trace, não deve ser confundido nem com traço, pois se refere "a marcas deixadas por uma ação ou pela passagem de um ser ou objeto" e, por isso, usam o termo "rastro" (1973, p. 22). Opto pelo usa do termo "traço" para seguir o sentido da teorização de Spivak.

17 Spivak se apega por vezes, assim como Paul de Man também o faz, aos erros ou traduções errôneas pelo efeito e, em especial, pela violência epistêmica que elas ensejam em sua crítica pós-colonial e desconstrucionista. a um movimento dialógico entre o eu e o outro. Por isso, Spivak prefere pensar no traço como essa percepção de uma tradução que não pode ser efetuada a contento do que pensar no hibridismo que asseguraria a possibilidade de tradução cultural irredutível, como parece sugerir Homi Bhaba (1994) e outros críticos pós-coloniais. Assim, a autora contrasta uma noção confortável de um hibridismo permissivo a uma ideia de traço, pois o hibridismo pressuporia, em sua visão, uma garantia de uma tradução cultural no contexto de uma política global assimiladora que seria a "face global do hibridismo como tradução" (2005b, p. 105). Spivak fala aqui do risco de se conceber o hibridismo acrítico por pressupor que ele levaria a uma possibilidade de uma tradução cultural confortável e sem conflitos - o que não acontece com grande parte dos migrantes que tem que enfrentar um estado repressivo e um racismo dominante.

Negar o direito à tradução ou efetuar uma tradução equivocada, como as cenas que abrem este trabalho evocam, instaura, assim, uma violência epistêmica, ${ }^{17}$ que revela uma falta de responsabilidade ética, e um silenciamento do subalterno: "roubar a língua materna do subalterno por meio de uma definição autoritária ignorante que já está se tornando parte da aceita lexicografia benevolente é um silenciamento profundo" (1994b, p. 64). Essa é a "violência da política da tradução como transcodificação" que permeia a indústria contemporânea da tradução (2005a, p. 47). De um lado está o mercado editorial internacional ávido por traduções das margens, de outro o dever e a obrigação da "constituição do sujeito da reparação". E, assim, "traduzimos em algum lugar entre essas extremidades" (2005a, p. 51). Ao clamar pela intimidade com o texto que requer que o/a tradutor/a dessa língua tenha conhecimento e familiaridade com o contexto e um forte senso do terreno específico do "original", a preocupação de Spivak é com a responsabilidade do/a tradutor/a que traduz 
de uma língua minoritária ou em vias de extinção para uma majoritária, como o inglês (uma tradução do idioma para a língua padrão), como aquelas situações evocadas nas cenas iniciais deste trabalho, e com o risco da "violência geral da culturação como tradução incessante e pendular" (2005a, p. 46).

Dessa forma, a tradução cultural se coloca no terreno ambíguo das transações e das relações culturais em zonas de contato assimétricas (PRATT, 1995). Spivak problematiza as transmissões culturais entre o centro e as culturais marginais, demonstrando a desmedida e a violência de uma tradução que está alheia tanto à responsabilidade quanto à cumplicidade do/a tradutor/a, atentando para a necessidade de estarmos sempre "vigilantes". É preciso ainda proceder a uma crítica persistente à "permeabilidade restrita de traduções culturais e linguísticas", isto é, ao fato de que "ninguém jamais traduzirá da língua fulani ou maya-quiché", por exemplo, sem uma agenda ou interesse específicos, por vezes, escusos (2001, p. 17). Um possível fracasso epistemológico da tradução discursiva revelaria a dificuldade (mas também a necessidade) de fazer o movimento de compreensão entre línguas e culturas diferentes, o qual deveria estar no cerne do conceito de tradução cultural. É a preocupação com esse "fracasso da tradução responsável" que permeia seus textos mais recentes sobre a tradução (2005b, p.104). É nesse sentido que podemos pensar sua teoria da tradução como uma proposta teórica de intervenção e interrupção. É também uma forma de se posicionar diante do fenômeno da demanda desmesurada por

18 Ver uma proposta similar de inserção dos estudos da tradução na literatura comparada em Basnett (1993, 2006), embora haja entre ambas uma posição bem distinta com relação a tais propostas.

19 Sobre o conceito e a discussão sobre a equivalência, ver Rodrigues, 2000. Spivak não se propõe, porém, a pensar a equivalência como "possibilidade de reconstrução das características sintáticas ou semânticas fundamentais do texto original" (2000, p. 217). Spivak pensa a equivalência segundo outros parâmetros que não os linguísticos comumente associados à noção tradicional do termo. Apesar de invocar a "existência de uma substância universal anterior a qualquer língua" (2000, p. 218), Spivak não crê na transferência estável de significados. traduções, em especial literárias, consideradas uma forma rápida de conhecer uma cultura. Implícita nesse argumento está a preocupação de que a tradução se torne, no contexto transnacional, uma forma de predominância linguística e cultural exercida por uma língua hegemônica (em contextos sempre relacionais). Dessa forma, torna-se cada vez mais importante traduzir de uma língua minoritária ou "menor", assim como traduzir do "idioma" ou de uma língua em extinção para o padrão, resguardados o respeito e a responsabilidade ética ao traço do outro.

\section{Literatura comparada como tradução}

Uma possível maneira de articular a tradução cultural nesse contexto estaria na proposta de Spivak de se pensar em uma literatura comparada em bases similares a sua teorização sobre a tradução no trânsito entre o centro e a periferia, ${ }^{18}$ pois "quando pensamos no comparativismo, pensamos na tradução" (2009, p. 613). Sua teorização acerca do conceito de equivalência tradutória resgata e redimenciona a noção de Jakobson - um conceito questionado por sua suposta inviabilidade linguística - e a desloca para o centro do impulso comparatista. ${ }^{19}$ No contexto de uma prática tradutória na literatura comparada, 
Spivak define esse impulso como sendo o aprendizado de que há uma equivalência entre as línguas, isto é, um respeito a ser conferido a todas as línguas de forma equivalente. Ao sugerir que pensemos nesses termos, seu objetivo é teorizar uma literatura comparada diferente daquela hierarquizada e predominante cujo foco central são os nacionalismos e os regionalismos europeus ocidentais e que tratam não de uma questão de comparar e contrastar, mas frequentemente de julgar, escolher e mesmo excluir. O comparativismo como equivalência efetuaria, assim, a reversão de uma leitura meramente nacionalista, desfazendo injustiças históricas associadas a línguas e grupos subalternos, marginalizados, negligenciados. A equivalência entre as línguas pode levar a um aprendizado profundo do ato tradutório nesses espaços não hegemônicos, pois "a tradução é de fato uma questão de poder" (2008 p. 10). O desafio da literatura comparada se situa, portanto, na abertura para o outro, e para as outras línguas e literaturas, produtivamente fazendo com que desaprendemos as monoculturas reproduzidas pelos impérios. Esse é um trabalho a ser feito por uma imaginação treinada nos jogos da linguagem ou das linguagens e no trabalho tradutório através de uma literatura comparada multilíngue, que abra espaço para as literaturas ditas nativas, e que ofereça a promessa da equivalência em espaços e tempos subalternos. Assim, um exercício de leitura no lastro de uma prática comparatista - indissociável de uma prática tradutória - deve se pautar também pela ética da responsabilidade no processo instável e insólito de tradução cultural.

\section{Outras traduções: leituras, equivalências, comparativismos}

${ }^{20}$ Sherry Simon vê nessa possível dualidade do texto de Spivak, uma longa tradição de um debate e um paradoxo que remonta a Goethe e seu conceito de Weltliteratur, ou seja, uma literatura mundial que incluiria as muitas diversidades de expressão literárias nacionais. $\mathrm{O}$ paradoxo, segundo Berman (1984) estaria na oscilação entre dois polos: por um lado um movimento no qual as culturas se traduziriam umas a outras, por outro na constituição em culturas nacionais hegemônicas mais fortes (Simon, 1996, p. 145).
Dessa forma, podemos indagar, como pensar a tradução principalmente na contemporaneidade? Ela seria uma forma de hospitalidade, nos termos que procurei elaborar, ou uma expressão da lei do mais forte? ${ }^{20}$ Se, por um lado, Spivak traz a voz do subalterno para o centro da teorização sobre tradução e a literatura comparada; por outro, seu discurso oscila perigosamente entre dois polos dicotômicos, entre a esperança de uma utopia irrealizável de uma responsabilidade ética para com o outro (o ideal libertário da tradução) e a crença na impossibilidade de agenciamento e, por conseguinte, no fracasso da tradução cultural (da tradução sempre como uma violação). No entanto, podemos pensar nesse posicionamento não como um paradoxo, uma dualidade, mas como uma relação intrínseca entre o ato tradutório, seu (ab)uso ideológico e político e a posição de intelectuais que trabalham com a tradução e a literatura comparada em tempos e espaços transnacionais e também periféricos. Se a tradução está inevitavelmente atrelada a uma lei do mais forte, cabe então a proposta de transgredi-la, como já mencionam nossos mais renomados teóricos da tradução da década de 70 e 80 
${ }^{21}$ Ver a crítica de Heloisa Buarque de Holanda ao tropo da carnavalização e da antropofagia no modernismo brasileiro ("The Politics of Cultural Studies", disponível em: http://www. pacc.ufrj.br/heloisa/ studies1.html)

22 Ver também a intrínseca relação da teorização de Santiago com o argumento de Bhabha sobre a tradução cultural contemporânea e sua relação com a noção de entre-lugar, embora ambos as enfoquem de maneiras distintas: "A cultura migrante do 'entre-lugar', a posição minoritária, dramatiza a atividade da intraduzibilidade da cultura; ao fazê-lo, desloca a questão da apropriação da cultura para além do sonho assimilacionista, ou do pesadelo racista, de uma 'transmissão total do conteúdo', em direção a um encontro com o processo ambivalente da cisão e hibridação que marca a identificação com a diferença da cultura" (BHABHA, 2001, p. 308).
- Augusto de Campos, Haroldo de Campos e Silviano Santiago -, que apresentam uma postura "revolucionária" a respeito do tema. Diferentemente desses, como procurei demonstrar, Spivak elabora uma teoria comparada da tradução através da lei da responsabilidade ética e da hospitalidade que faz com que o/a tradutor/a resguarde o espaço ocupado pelo subalterno, sua língua e sua cultura, no trabalho de tradução do idioma para o padrão. A teoria da transcriação, transtextualização ou transluciferação de Haroldo de Campos (a partir também de Augusto de Campos), como sabemos, efetua uma transgressão por meio da apropriação da energia vital do outro e da assimilação de conhecimento a partir de sua "deglutição", em uma alusão à antropofagia e ao canibalismo do modernismo de Oswald de Andrade. Refere-se, assim, à forma como digerimos o que vem de fora e procedemos a uma tradução criativa ou usurpadora em um ato de transgressão com relação ao elemento estrangeiro e hegemônico, ${ }^{21}$ encenando uma tradução da literatura ocidental para uma marginalizada, ou, nos termos de Spivak, do padrão para o idioma. De forma similar, Silviano Santiago discorre, em seu consagrado texto "O entre-lugar do discurso latino-americano" (1971), sobre uma tradução "transformadora" (no sentido tanto de Derrida quanto de Benjamin) que efetua "a agressão contra o modelo, a transgressão ao modelo proposto" pela "necessidade de produzir um novo texto que afronte o primeiro e muitas vezes o negue" (2000, p. 23-24). Assim, o conhecimento concebido como produção dá contorno à transgressão como forma de se expressar, como um conhecimento que vem de fora e que é assimilado e traduzido pelo escritor latino-americano que realiza seu "ritual antropofágico" no entre-lugar "entre o sacrifício e o jogo, entre a prisão e a transgressão, entre a submissão ao código e a agressão entre a obediência e a rebelião, entre a assimilação e a expressão" (2000, p. 26). ${ }^{22}$

A teorização dos irmãos Campos, assim como a de Santiago, revela um caminho reverso àquele trilhado por Spivak. No entanto, Santiago inicia seu texto com uma reflexão que se aproxima daquela elaborada por Spivak. Ao refletir sobre o processo de colonização na América Latina, Santiago afirma: "o código linguístico e o código religioso se encontram intimamente ligados, graças à intransigência, à astúcia e à força dos brancos. Pela mesma moeda, os índios perdem sua língua e seu sistema do sagrado e recebem em troca o substituto europeu". Santiago continua: "evitar o bilinguismo significa evitar o pluralismo religioso e significa impor o poder colonialista" (2000, p. 14). Essa é a violência epistêmica sobre a qual nos fala Spivak. É em resposta a essa violência na contemporaneidade que a autora delineia sua teoria da tradução responsável e ética. Se Santiago nos revela um aspecto de nosso passado 
colonial, do silenciamento do subalterno e do apagamento de sua língua, a teoria da tradução de Spivak atenta para o risco de esse passado se perpetuar no nosso atual momento transnacional (daí a necessidade de estarmos sempre "vigilantes"). A proposta de Spivak, em minha análise, não é incompatível com aquela elaborada pelos irmãos Campos e por Santiago em sua visão do papel da tradução como instrumento através do qual uma crítica à cultura e à colonização do pensamento e do conhecimento se efetua. Tanto os irmãos Campos e Santiago quanto Spivak oferecem uma crítica por meio de uma mirada periférica através do descentramento dos estudos da tradução cultural, apresentando dois lados de um mesmo fenômeno e teorizando a partir de um outro lugar não hegemônico. Spivak problematiza as transmissões culturais entre o centro e as culturas marginais - assim como o fazem Augusto e Haroldo Campos e também Santiago, mas por outro viés. Em comum, pode-se discernir o conceito de hospitalidade dado ao outro, seja esse o grande Outro lacaniano, cujo discurso é subvertido, ou o outro subalterno, cujo discurso é respeitado. Ao invés de "canibalizar o acervo acidental" como querem os irmãos Campos, nas palavras de Costa Lima (1991, p.16), Spivak desestabiliza esse mesmo acervo ao propor a inserção do discurso do outro subalterno por meio da tradução responsável e ética. Se para Campos e Santiago a transgressão é essencial para vencer a dependência e o neocolonialismo e a tradução/transcriação um ato de rebeldia e apropriação (do centro pela periferia), Spivak endossa um questionamento que também deve surgir da periferia para desestabilizar o centro, mas através de um ato de responsabilidade e aprendizado éticos para com a tradução da língua do subalterno, que se tornou uma mercadoria rentável e fetichizada - no sentido que hoje se procura cada vez mais conhecer a língua do outro para explorá-lo ou falar por ele, como nos relata Cardinal na cena apresentada no início deste texto.

Assim, Spivak procura com sua crítica responder à indagação: "o que significa ser uma leitora pós-colonial do inglês no século 20?" (1993, p. 198). E eu perguntaria, o que significa ser uma leitora (como tradutora) de Spivak no século 21, em um país na periferia da produção cultural, em um contexto marcadamente transnacional, longe, no entanto, de ser pós-nacional? Significa, a meu ver, estar também sempre vigilante, como clama Spivak, questionando o próprio lugar de onde se fala, nos termos propostos por Edward Said. Ao atuar como mediadora - imagem recorrente do processo tradutório - e tradutora do pensamento de Spivak, meu ato também se configura como ambivalente e se desloca ambiguamente no terreno movediço da tradução linguística e cultural para então poder teorizar sobre ela, ciente do incômodo lugar que teoriza o próprio espaço mediador no qual habita, no entre-lugar, na ambivalência não menos típica do 
discurso latino-americano de Santiago. A minha é também uma mirada periférica que procura desestabilizar os processos tradutórios neste espaço enunciativo, marcadamente comparados. Interessa-me, em especial, a insistência de Spivak em desafiar os discursos hegemônicos e também nossas próprias crenças como leitores e produtores de saber e conhecimento, pensando a teoria crítica e, em especial, a tradução cultural - ou mesmo a tradução como cultura - e a literatura comparada como uma prática intervencionista, engajada e desestabilizadora que efetua uma fratura epistemológica e insere uma mirada revigorada tanto no campo discursivo quanto na esfera de uma atividade política contestadora. É esse traço de Spivak que faz com seus trabalhos teóricos, mesmo com a complexidade (e mesmo hermetismo) que lhes é peculiar, ultrapassem, como demonstra Terry Eagleton (2005), as barreiras do academicismo, refletindo sobre questões de ideologia, poder e agenciamento e nosso papel como críticos, intelectuais e tradutores na e da contemporaneidade, aludindo tanto à produção cultural quanto à realidade sócio-histórica e falando de uma tradição crítica a partir de um discurso que privilegia a periferia e a margem do sistema globalizado como um espaço fecundo de produção teórica e discursiva.

Retorno agora brevemente às três cenas com as quais iniciei esta fala. Elas evocam, de formas distintas, o impasse, o double bind do ato tradutório transcultural, quer seja pela responsabilidade e dificuldade da tradução eticamente referenciada, como no caso do romance $A$ tradutora; pelo fracasso e violação da tradução e do direito de falar relatados por Cardinal, ou pela exotização e silenciamento do sujeito subalterno, como no caso de Carolina Maria de Jesus. Esses episódios prefiguram traduções culturais que instalam o desconforto e evidenciam uma suposta pretensão de transparência tradutória que desloca o conceito de tradução, instaurando a fratura e mesmo o fracasso em seu cerne. É esse ato de tradução cultural que mesmo irresoluto marca um espaço de reinscrição que delineia a emergência de um outro possível signo de agenciamento (nos termos de Bhabha, 1994) que requer que os tradutores culturais -neste caso, a tradutora Sammar, o governo canadense, o mediador - se coloquem diante de seus sujeitos/objetos de maneira ética e responsável mesmo como um impulso utópico. Somente assim poder-se-á reescrever a costumeira percepção da tradução que não se efetua jamais e que se torna por vezes "uma perda de uma conexão de vida", como nos lembra a escritora Eva Hoffman no romance Lost in Translation [Pedidos na tradução] (1989, p. 78), e resgata a proposta de uma tradução cultural que oferta a dádiva da escuta qualificada ao outro e, em especial, ao subalterno. 


\begin{abstract}
The essay addresses the contemporary concept of cultural translation and focuses, especially, on Gayatri Chakravorty Spivak's theorizations, discussing the relation between translation and subalterneity, solidarity and comparative literature.
\end{abstract}

Key-words: transcultural translation; subalterneity; solidarity; comparative literature.

\title{
REFERÊNCIAS
}

ABOULELA, Leila. The Translator. New York: Black Cat, 1999.

ARROJO, Rosemary. Oficina da tradução: a teoria na prática. São Paulo: Ática, 1986.

ASCHER, Nelson. O texto e sua sombra: teses sobre a teoria da intradução. Revista 34 Letras n. 3, Rio de Janeiro, p. 150, 1989.

BAKHTIN, M.M. The Dialogic Imagination. Trad. Caryl Emerson and Michael Holquist. Austin: University of Texas Press, 1982.

BASSNET, Susan. Reflections on Comparative Literature in the Twenty-First Century. Comparative Critical Studies v. 3, n. 1-3, p. 3-11, 2006.

BASSNET, Susan; TRIVEDI, H. (Eds.). Post-colonial Translation. London and New York: Routledge, 1999.

BENJAMIN, Walter. A tarefa-renúncia do tradutor. Trad. Susana Kampf Lages. In: HEIDERMANN, Werner (Org.). Clássicos da teoria da tradução. Florianópolis: UFSC, 2001. p. 189-215.

BERMAN, Antoine. L'épreuve de l'étranger: culture et traduction dans l'Allemagne romantique. Paris: Gallimard, 1984.

BHABHA, Homi. The Location of Culture. New York: Routledge, 1994.

CAMPOS, Augusto de. Verso, reverso, controverso. São Paulo: Perspectiva, 1978.

CAMPOS, Haroldo de. Da tradução como criação e como crítica. In: 1992. p. 31-48. . Metalinguagem e outras metas. São Paulo: Perspectiva, tiva, 1981.

. Deus e o Diabo no Fausto de Goethe. São Paulo: Perspec-

. Da transcriação: poética e semiótica da operação tradutora. In: OLIVEIRA, Ana Cláudia de; SANTAELLA, Lúcia (Orgs.). Semiótica da literatura. São Paulo: EDUC, 1987. p. 53-74.

CARDINAL, Harold. A Canadian What the Hell It's All About. In: MOSES, Daniel David; GOLDIE, Terry. An Anthology of Canadian Native Literature in English. Toronto: Oxford University Press, 1992. p. 188-194. 
COMPAGNON, Antoine. O trabalho de citação. Trad. Cleonice P. B. Mourão. Belo Horizonte: Editora UFMG, 1996.

DANTAS, Audálio. A atualidade do mundo de Carolina. In: JESUS, Carolina Maria. Quarto de despejo: diário de uma favelada. São Paulo: Editora Ática, 2001. p. 3- 5

DERRIDA, Jacques. Des tours de Babel. In: GRAHAM, Joseph (Ed.). Difference in Translation. Ithaca: Cornell University Press, 1985. p. 165-207.

. Dissemination. Trans. Barbara Johnson. Chicago: University of Chicago Press, 1981.

. Given Time: Counterfeit Memory. Trans. Peggy Kamuf. Chicago: University of Chicago Press, 1992.

- Gramatologia. Trad. Miriam Schnaiderman e Renato Janine Ribeiro. São Paulo: Perspectiva/Edusp, 1973. Press, 1982.

Positions. Trad. Alan Bass. Chicago: University of Chicago

Of Grammatology. Trans. Gayatri Chakravorty Spivak. Baltimore and London: The Johns Hopkins University Press, 1976. 1987.

. Positions. Trad. Alan Bass. London: The Athlone Press,

. Torre de Babel. Trad. Junia Barreto. Belo Horizonte: Editora UFMG, 2006.

DERRIDA, Jacques; DUFOURMANTELLE, Anne. Da hospitalidade. Anne Dufourmantelle convida Derrida a falar da hospitalidade. Trad. Antonio Romane. São Paulo: Escuta, 2003.

EAGLETON, Terry. Gayatri Spivak. In: Figures of Dissent: Critical Essays on Fish, Spivak, Žižek, and Others. London and New York: Verso, 2005. p. 158-167.

FRIEDMAN, Susan Stanford. The "New Migration": Clashes, Connections and Diasporic Women's Writing. Contemporary Women's Writing, Oxford, v. 3, n. 1, p. 6-27, June 2009.

GRAHAM, Joseph (Ed.). Difference in Translation. Ithaca: Cornell University Press, 2000.

HOFFMAN, Eva. Lost in Translation. London and New York: Routledge, 1989.

JAKOBSON, Roman. Aspectos linguísticos da tradução. In :

Linguística e comunicação. Trad. Izidoro Blikstein e José Paulo Paes. São Paulo: Cultrix, 1971. p. 63-72.

JESUS, Carolina Maria. Quarto de despejo: diário de uma favelada. São Paulo: Editora Ática, 2001.

KRISTEVA, Julia. La révolution du langage poétique. Paris: Éditions du Seuil, 1974. 
LAGES, Susana Kampff. Walter Benjamin: tradução e melancolia. São Paulo: EDUSP, 2007.

PAPASTERGIADIS, Nikos. The Limits of Cultural Translation. In: ___. The Turbulence of Migration. Cambridge: Polity Press, 2000. p. 122-138.

PRATT, Mary Louise. Imperial Eyes: Travel Writing and Transculturation. London and New York: Routledge, 1995.

REGO, Cláudia de Morais. Traço, letras, escrita - Freud, Derrida, Lacan. Rio de Janeiro: 7 Letras, 2006.

RODRIGUES, Cristina Carneiro. Tradução e diferença. São Paulo: UNESP, 2000.

SANTIAGO, Silviano. O entre-lugar do discurso latino-americano. In: 2000. p. 9-26. Uma literatura nos trópicos. Rio de Janeiro: Rocco,

SIMON, Sherry. Gender in Translation: Cultural Identity and the Politics of Transmission. London and New York: Routledge, 1996.

Introduction. In: SIMON, Sherry; ST-PIERRE, Paul (Eds.). Changing the Terms: Translating in the Postcolonial Era. Ottawa: University of Ottawa Press, 2000. p. 9-29.

. La culture transnationale en question: visées de la traduction chez Homi Bhabha et Gayatri Spivak. Études françaises v. 31, n. 3 , p. 43-57, 1995.

SPIVAK, Gayatri Chakravorty. A Critique of Postcolonial Reason: Toward a History of the Vanishing Present. Cambridge: Harvard University Press, 1999a.

. Can the Subaltern Speak? In: NELSON, Cary; GROSSBERG, Larry (Eds.). Marxism and the Interpretation of Culture. Urbana: University of Illinois Press, 1988. p. 271-313.

. Claiming Transformation: Travel Notes with Pictures. In: AHMED, Sara; KILBY, Jane; LURY, Celia; MACNEIL, Maureen; SKEGGS, Beverly. Transformations: Thinking Through Feminism. London and New York: Routledge, 2000a. p. 119-130.

Press, 2003.

. Death of a Discipline. New York: Columbia University

. Diaspora Old and New: Women in Transnational World.

Textual Practice, v. 10, n.2, p. 245-269, 1996 a. Methen, 1987.

In Other Worlds: Essays in Cultural Politics. New York:

. Imperatives to Re-imagine the Planet. Wien: PassagenVerlag, 1999b.

More Thoughts on Cultural Translation. April 2008. Disponível em: http://translate.eipcp.net/transversal/0608/spivak/en/ print. Acesso em: 29 setembro 2010. 
. Nationalism and the Imagination. London, New York, Calcutta: Seagull, 2010a.

. Other Asias. New York: Blackwell, 2008.

. Outside in the Teaching Machine. New York and London: Routledge, 1993.

. Pode o subalterno falar? Trads. Sandra Regina Goulart Almeida, Marcos Pereira Feitosa, André Pereira Feitosa. Belo Horizonte: Editora UFMG, 2010b.

. The Politics of Translation. In: . Outside in the Teaching Machine. London and New York: Routledge, 1993. p. 179-200.

. Quem reivindica alteridade? Trad. Patricia Silveira de Farias. In: HOLLANDA, Heloisa Buarque de. Feminismo em tempos pós-modernos. Rio de Janeiro: Rocco, 1994a. p. 187-205.

. Questioned on Translation: Adrift. Public Culture v. 13, n. 1, 2001, p. 13-22.

. Responsibility. Boundary 2: An International Journal of Literature and Culture, Durham, NC, v. 21, n.3, 1994b, p. 19-64. . Rethinking Comparativism. New Literary History n.40, v. 3, p. 609-626, 2009.

. Teaching for the Times. In: MCCLINTOCK, Anne; MUFTI, Aamir; SHOHAT, Ella (Eds.). Dangerous Liaisons: Gender, Nation \& Poscolonial Perspectives. Minneapolis: University of Minnesota Press, 1997. p. 468-490.

. Translation as Culture. Parallax v. 6, n.1, p. 13-24, 2000 b.

Tradução como cultura. Trad. Eliana Ávila e Liane Schneider. Ilha do Desterro, Florianópolis, v. 48, p. 41-64, $2005 a$.

. Translation into English. In: BERMANN, Sandra; WOOD, Michael. Nation, Language and the Ethics of Translation. Princeton: Princeton University Press, 2005b. p. 93-110.

. Translator's Preface and Afterword to Mahasweta Devi, Imaginary Maps.In: ____. The Spivak Reader. New York and London: Routledge, 1996b. p. 267-286.

. Translator's Preface. In: DERRIDA, Jacques. Of Grammatology. Baltimore and London: The Johns Hopkins University Press, 1976. p. ix-lxxxvii.

SPIVAK, Gayatri Chakravorty; BUTLER, Judith. Who Sings the Nation-State? London, New York, Calcutta: Seagull, 2007.

VIEIRA, Else R. P. Liberating Calibans: Readings of Antropofagia and Haroldo de Campos' Poetics of Transcreation. In: BASSNET, Susan; TRIVEDI, H. (Eds.). Post-colonial Translation. London and New York: Routledge, 1999. p. 95-113.

. Por uma teoria pós-moderna da tradução. Belo Horizonte, 1992. 248p. Tese (Doutorado em Letras/Literatura Comparada) - FALE, UFMG. 